\title{
PORCENTAGEM DE LACTOSE EM AMOSTRAS DE LEITE DE TANQUE NO ESTADO DO PARANÁ
}

\author{
(Percentage of lactose in bulk tank milk in the state of Paraná)
}

\author{
Newton Pohl Ribas ${ }^{1}$, José Augusto Horst ${ }^{2}$, Uriel Vinicius Cotarelli Andrade ${ }^{3}$, Hendyel \\ Aparecida Pacheco ${ }^{1}$, Andressa Regonato ${ }^{1}$ \\ 1 Correspondência: newtonribas.ufpr@gmail.com \\ 1. Universidade Federal do Paraná-UFPR; ${ }^{2}$. Associação Paranaense de Criadores de Bovinos da Raça \\ Holandesa-APCBRH; ${ }^{3}$. Faculdade Evangélica do Paraná-FEPAR
}

\begin{abstract}
RESUMO: Programas de gerenciamento de rebanhos leiteiros têm utilizado a porcentagem de lactose na avaliação da qualidade do leite. Foram avaliados os efeitos de meio ambiente sobre a \% de lactose de amostras de tanques coletadas mensalmente pelas indústrias de laticínios do Estado do Paraná, analisadas pelo Laboratório da Qualidade do Leite (LQL) da Associação Paranaense de Criadores de Bovinos da Raça Holandesa (APCBRH), fruto do convênio com UFPR. Analisaram-se 1.950.034 amostras de leite, coletadas no período de janeiro de 2005 a abril de 2012, em dez regiões do Estado. As médias estimadas, desvios-padrão e Coeficiente de Variação para \% Lactose, ECS e Idade da Amostra em dias foram: 4,40 $\pm 0,23,4,61 \%$; 4,83 $\pm 1,52,30,06 \%$; e 2,98 $\pm 1,57$ dias, respectivamente. Todos os efeitos incluídos no modelo matemático (mês e ano de análise, região, idade da amostra e escore da contagem de células somáticas) influenciaram significativamente $(\mathrm{P}<0,01)$ a variável estudada. $O \mathrm{R}^{2}$ estimado foi de $0,23 \%$ para \% de lactose. Os maiores valores observados de \% de lactose ocorreram nos meses de agosto e setembro (4,48 e 4,48\%) respectivamente e os menores em abril e maio (4,37 e 4,36\%). O efeito de ano registrou um aumento linear de 2005 (4,38\%) para $2012(4,49 \%)$. Para o efeito de região, as maiores médias ocorreram na região Sudoeste-Francisco Beltrão (4,50\%) e na região Centro Oriental-Ponta Grossa $(4,46 \%)$, entretanto, as menores foram observadas nas regiões Norte Pioneiro -Cornélio Procópio $(4,40 \%)$ e Sudeste - Irati (4,40\%). A idade da amostra apresentou a maior média com 2 dias (4,44\%), todavia o menor valor foi observado com 6 dias $(4,42 \%)$. A \% de lactose apresentou correlação alta e negativa com o ECS $(-0,420),(P<0,01)$, ao variar de zero a oito a \% de lactose diminuiu de 4,63 para 4,14\%.
\end{abstract}

Palavras-chave: ano de análise; escore da contagem de células somáticas; idade da amostra; mês de análise; região

\begin{abstract}
Management of dairy herds programs has used the percentage of lactose in assessing the quality of milk. The effects of the environment on \% lactose samples collected monthly by the tanks of the State of Paraná dairy industries, analyzed by the Laboratory's Quality Milk (LQL) of Paraná Association of Cattle Breeders of Holstein (APCBRH) were evaluated as a result of the agreement with UFPR. We analyzed 1,950,034 milk samples collected from January 2005 to April 2012 , in ten regions of the state. The estimated averages, standard deviations and coefficient of variation for\% Lactose, ECS and Sample Age in days were: $4.40 \pm 0.23,4.61 \%$; $4.83 \pm 1.52,30.06 \%$; and $2.98 \pm 1.57$ days, respectively. All the variables included in the mathematical model (month and year of analysis, region, age of the sample and score the somatic cell count) significantly influenced $(P<0.01)$ the variable studied. The $R^{2}$ of $0.23 \%$ was estimated for \% lactose. The largest observed values of \% lactose occurred in the months of August and September (4.48) and (4.48) respectively, lower in April and May (4.37) and (4.36). The effect of year recorded a linear increase from 2005 (4.38) to 2012 (4.49). For the effect of region, the highest averages occurred in the Southwest region - Francisco Beltrão (4.50) and East Central - Ponta Grossa (4.46), however, the lowest were observed in the North Pioneer - Cornélio Procópio $(4,40)$ and Southeast - Irati (4.40). The age of the sample was characterized with the highest average 2 days (4.44), but the lowest value was observed for 6 days $(4.42)$. The\% lactose, and had a high negative correlation with the ECS $(-0.420)(P<0.01)$ to vary from zero to eight to $\%$ lactose decreased from 4.63 to $4.14 \%$.
\end{abstract}

Key Words: year of analysis; score of somatic cell count; age of the sample; month analysis; region 


\section{INTRODUÇÃO}

Segundo 0 Departamento de Economia Rural (DERAL) da Secretaria de Estado da Agricultura e do Abastecimento (SEAB), o Estado do Paraná é o 3 o maior produtor nacional de leite, com uma produção de 3,59 bilhões de litros, participando com $11,7 \%$ da produção brasileira (MEZZADRI, 2012).

A caracterização socioeconômica da atividade leiteira do Paraná registrou a estimativa de 114.488 produtores de leite no Estado, sendo que $87 \%$, ou seja, 99.573 produtores comercializam a produção de leite (IPARDES, 2009).

O estudo do IPARDES (2010) de caracterização da indústria de processamento e transformação do leite no Paraná relata 353 unidades industriais processadoras

transformadoras de leite, localizadas em 180 municípios, sendo 101 unidades sob SIF, 126 sob SIP e 126 unidades sob SIM.

A caracterização racial do rebanho leiteiro paranaense apresenta: $28,4 \%$ de animais da raça Holandesa, 5,7\% Jersey, $17,7 \%$ Girolanda, 8,0\% PardoSuíça e 40,2\% não possuem raça definida, segundo KOEHLER (2000) e IPARDES (2004).

Visando melhorar a qualidade do leite, foi implantado pelo Ministério da Agricultura, Pecuária e Abastecimento (MAPA) o Programa Nacional de Melhoria da Qualidade do Leite (PNMQL), através da IN 51 (BRASIL, 2002), visando adequar os produtos lácteos aos padrões internacionais, proteger o mercado interno da entrada de produtos de baixa qualidade, obter um produto competitivo no mercado internacional, assegurando o máximo de rendimento industrial e fornecer ao consumidor brasileiro um produto com maior valor nutritivo, maior durabilidade, mais seguro e de baixo custo.

Em 2011 o MAPA alterou a IN 51 (BRASIL, 2002), editando a IN 62
(BRASIL, 2011), contendo novas normas para vigorar a partir de 01/01/2012 estabelecendo parâmetros para componentes do leite, contagem de células somáticas e contagem bacteriana.

Para o monitoramento mensal da qualidade do leite, indústrias de laticínios do Estado do Paraná em atendimento ao PNMQL do MAPA se utilizam dos serviços do Laboratório de Análise da Qualidade do Leite (LQL) do Programa de Análise de Rebanhos Leiteiros do Paraná (PARLPR) da Associação Paranaense de Criadores de Bovinos da Raça Holandesa (APCBRH), fruto do convênio com a UFPR, credenciado pelo MAPA e participante da Rede Brasileira de Qualidade do Leite (RBQL).

Bases de dados do desempenho zootécnico de rebanhos são ferramentas essenciais para o manejo racional dos animais, para os programas de avaliação genética de gado leiteiro, programas de rastreabilidade de animais e produtos lácteos e para 0 planejamento estratégico da cadeia láctea (DÜRR et al., 2011).

A importância da \% de Lactose nos vários processos tecnológicos a que se submete o leite é evidente, pois é o principal fator nos processos de acidificação do leite (fermentação e maturação), está relacionada com o valor nutritivo, textura e solubilidade, desempenhando papel preponderante na cor e sabor de produtos (OLIVEIRA e CARUSO,1996).

Segundo Shuster et al. (1991), as mudanças na concentração de lactose durante a mastite podem ocorrer devido à passagem de lactose do leite para 0 sangue, que pode ser comprovado pelas elevadas concentrações de lactose no sangue e na urina de vacas com mastite. Adicionalmente, a lesão tecidual ocasionada pela mastite provoca redução da capacidade de síntese de lactose pelo epitélio glandular, afetando significativamente a quantidade do leite 
produzido, devido ao papel central da lactose como regulador osmótico do volume do leite.

O objetivo desta pesquisa foi avaliar os efeitos de meio ambiente, caracterizados como mês e ano de análise, região, idade de amostra e escore da contagem de células somáticas, que estariam influenciando as porcentagens de Lactose em amostras de leite de tanques.

\section{MATERIAL E MÉTODOS}

Para o estudo das porcentagem (\%) de Lactose, foram utilizadas 1.950.034 amostras refrigeradas de leite de tanques provenientes de propriedades localizadas em 10 regiões do Estado do Paraná - PR, analisadas no período de janeiro de 2005 a abril de 2012.

As amostras de leite de tanques foram coletadas mensalmente nas propriedades por pessoal treinado pelas indústrias de laticínios, segundo os procedimentos recomendados pelos manuais de Operações de Campo (HORST, 2008) e de Coleta de Amostras (HORST, 2010) do LQL do PARLPR da APCBRH. As amostras foram acondicionadas em frascos padronizados $(70 \mathrm{ml})$, utilizando-se do conservante bronopol (2-bromo-2-nitro propano-1,3-diol) e enviadas ao LQL.

O número de dias decorridos entre a coleta de leite na fazenda e sua análise no laboratório, Curitiba-PR, foi definido como sendo a idade da amostra.

Segundo Hartmann (1999), Ostrensky (1999) e Paula et al. (2004), visando melhor acurácia das análises para amostras de leite de bovinos, as seguintes restrições foram impostas ao banco de dados: CCS menor ou igual a zero e maior que 4.525 .000 células/ $\mathrm{mL}$; lactose menor que $1,5 \%$ e maior que
$6,5 \%$ e idade da amostra menor que um e maior que sete dias.

A análise da característica estudada foi realizada utilizando-se o seguinte modelo estatístico:

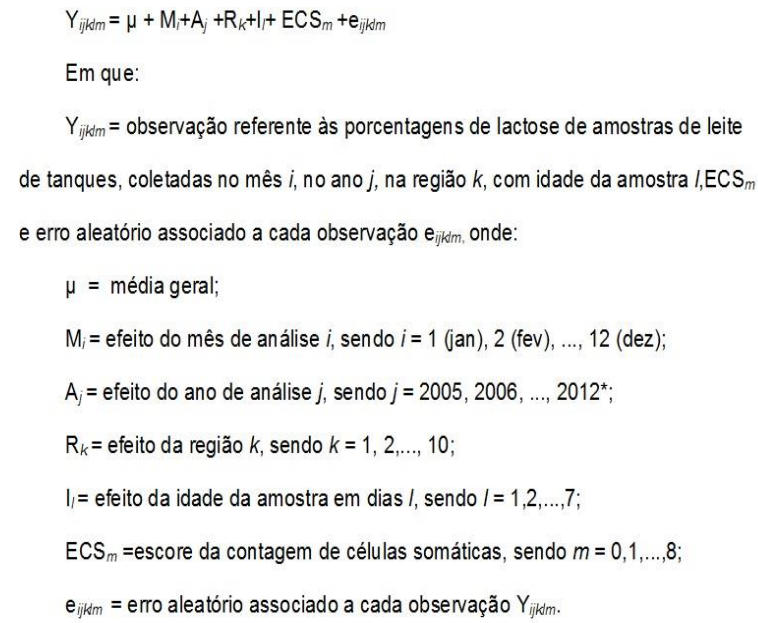

*o ano de 2012 está representado apenas por amostras de leite coletadas nos quatro primeiros meses do ano.

A variável CCS é o resultado da leitura do equipamento por citometria de fluxo, Somacount $500 \AA$ (BENTLEY INSTRUMENTS, 1995b), em mil células $/ \mathrm{mL}$; O ECS é o resultado da transformação logarítmica da CCS (ALI; SHOOK, 1980 e SHOOK, 1982), obtida pela equação $E C S=\log 2(C C S / 100)+3$. Os valores de ECS correspondentes ao intervalo de CCS de zero a 12.000 células/ $\mathrm{mL}$ foram forçados a serem iguais a zero, para se evitarem números negativos; as concentrações de lactose foram obtidas através do equipamento por leitura de absorção infravermelha, Bentley 2000®) (BENTLEY INSTRUMENTS, 1995a).

Segundo a classificação de Köppen (IAPAR, 1999) são identificados dois tipos climáticos no Estado do Paraná, Cfa e Cfb, descritos a seguir:

Cfa- Clima subtropical com temperatura média no mês mais frio inferior a $18^{\circ} \mathrm{C}$ (mesotérmico) e temperatura média no mês mais quente acima de $22^{\circ} \mathrm{C}$, verões 
quentes, geadas pouco frequentes e tendência de concentração das chuvas nos meses de verão, contudo sem estação seca definida, para as regiões noroeste (Umuarama), centro ocidental (Campo Mourão), norte central (Londrina), norte pioneiro (Cornélio Procópio), oeste (Cascavel) e sudoeste (Francisco Beltrão).

$$
\text { Cfb- Clima temperado }
$$

propriamente dito com temperatura média no mês mais frio abaixo de $18^{\circ} \mathrm{C}$ (mesotérmico), verões frescos, temperatura média no mês mais quente abaixo de $22^{\circ} \mathrm{C}$ e sem estação seca definida, para as regiões centro oriental (Ponta Grossa), centro sul (Guarapuava), sudeste (Irati) e metropolitana de Curitiba (Curitiba).

As análises dos dados foram realizadas adotando-se o programa computacional SASß versão 9.3 (2011) pelo modelo estatístico tipo III, utilizando-se dos seguintes procedimentos Proc Means, Proc Freq, Proc GLM e Proc Corr.

A comparação entre médias foi realizada por meio do Teste de Tukey a $1 \%$ de probabilidade.

\section{RESULTADOS E DISCUSSÃO}

$\mathrm{Na}$ Tabela 1, encontram-se as médias estimadas, respectivos desviospadrão e coeficientes de variação para: $\%$ lactose, CCST, ECS e idade da amostra: 4,40 $\pm 0,23 ; 4,61 \% ; 553 \pm 545$; $96,10 \% ; 4,83 \pm 1,52 ; 30,06 ; 2,98 \pm 1,57$ respectivamente.

\begin{tabular}{|c|c|c|c|c|c|}
\hline CARACTERISTICAS & $\mathrm{N}$ & MÉDIA & \pm & DP & CV(\%) \\
\hline \% Lactose & 1.950 .034 & 4,40 & \pm & 0,23 & 4,61 \\
\hline CCST & 1.950 .034 & 553 & \pm & 545 & 96,10 \\
\hline ECS & 1.950 .034 & 4,83 & \pm & 1,52 & 30,06 \\
\hline Idade da Amostra (dias) & 1.950 .034 & 2.98 & \pm & 1.57 & - \\
\hline
\end{tabular}

$\mathrm{Na}$ Tabela 2, apresentamos médias para \% de Lactose, de dezessete pesquisadores, que obtiveram 0 valor médio foi de $4,60 \%$. Todavia em países que estabeleceram programas de melhoria da qualidade do leite, como Nova Zelândia, as \% de Lactose são muito superiores àquelas estimadas por autores brasileiros e a desta pesquisa, variando de $4,83 \%$ a $4,97 \%$.

\begin{tabular}{lcc}
\multicolumn{3}{l}{$\begin{array}{l}\text { Tabela 2 } \text { Valores médios da \% de Lactose em amostras de } \\
\text { leite obtidos por diferentes pesquisadores. }\end{array}$} \\
\hline \multicolumn{1}{c}{ Autor (ano) } & País & $\begin{array}{c}\text { Média } \\
\text { \% de Lactose }\end{array}$ \\
\hline Alberton , J. (2012) & Brasil & 4,46 \\
Machado et al. (2000) & Brasil & 4,51 \\
Fonseca et. al. (2006) & Brasil & 4,51 \\
Noro (2004) & Brasil & 4,52 \\
Bueno (2004) & Brasil & 4,54 \\
Machado et al. (2003) & Brasil & 4,55 \\
Santos e Fonseca & Brasil & 4,56 \\
(2002 $)$ & Brasil & 4,56 \\
Perez Júnior et al. & Brasil & 4,59 \\
(2002) & Estados Unidos & 4,61 \\
Brito et al. (2003) & Brasil & 4,61 \\
Akers (2002) & Brasil & 4,61 \\
Mühlbach et al. (2000) & Brasil & 4,66 \\
Prada et al. (2000) & Brasil & 4,70 \\
Dürr (2003) & Nova \\
Duräes et al. (2001) & Zelândia & 4,83 \\
Auldist at al. (1998) & Nova Zelândia & 4,97 \\
NZDGC (2000) & & \\
\hline
\end{tabular}

O resumo da análise de variância para a característica estudada encontrase na Tabela 3, onde podemos observar que todos os efeitos incluídos no modelo estatístico foram significativos $(P<0,01)$.

Tabela 3- Resumo da análise de variância da lactose (\%) de amostras de leite, no estado do Paraná

\begin{tabular}{lcc}
\hline \multirow{2}{*}{ FONTE DE VARIAÇÃo } & \multirow{2}{*}{$\mathrm{GL}$} & \multicolumn{2}{c}{ QUADRADOS MÉDIOS } \\
\cline { 3 - 3 } & & $\%$ LACTOSE \\
\hline Mês de análise & 11 & $256,37^{* *}$ \\
Ano de análise & 7 & $254,57^{* *}$ \\
Região & 9 & $121,94^{* *}$ \\
Idade da amostra & 6 & $3,16^{* *}$ \\
${ }^{1} \mathrm{ECS}$ & 8 & $1.926,26^{* *}$ \\
\hline${ }^{2} \mathrm{R}^{2}$ & & 0,232 \\
${ }^{3} \mathrm{CV}(\%)$ & 4,61 \\
\hline${ }^{*}(\mathrm{P}<0,01)$ & \\
${ }^{1} \mathrm{ECS}:$ Escore de células somáticas \\
${ }^{2} \mathrm{R}^{2}:$ Variação total explicada pelos efeitos incluídos no \\
modelo \\
${ }^{3} \mathrm{CV}(\%)$ : Coeficiente de variação
\end{tabular}


O mês de análise influenciou significativamente as $\%$ de lactose $(P<0,01)$, como podemos observar no resumo da análise de variância (tabela $3)$.

$\mathrm{Na}$ Tabela 4, apresentamos maiores estimativas de médias ajustadas para as \% de lactose nos meses de agosto, setembro e outubro (final de inverno e início da primavera), respectivamente 4,$48 ; 4,48$ e $4,47 \%$. Estimativas menores foram nos meses de março, abril e maio (final do verão e início do outono), respectivamente 4,39; 4,37 e 4,36\%. Características de qualidade são influenciadas por variações de acordo com os meses ou estações do ano em que ocorrem os controles. Estas são justificadas por variações climáticas, de manejo, de qualidade dos alimentos, a que estão sujeitos os animais.

\begin{tabular}{|c|c|c|c|c|c|}
\hline \multirow{2}{*}{ MES DE ANALISE } & \multirow[b]{2}{*}{$\mathrm{N}$} & \multirow{2}{*}{$\%$} & \multicolumn{3}{|c|}{ \% LACTOSE } \\
\hline & & & Média $^{2}$ & \pm & EP \\
\hline Janeiro & 165.665 & 8,50 & $4,44^{9}$ & \pm & $0,00058^{\prime \prime}$ \\
\hline Fevereiro & 161.031 & 16,75 & $4,43^{\circ}$ & \pm & $0,00059^{-\prime}$ \\
\hline Março & 183.159 & 26,15 & $4,39^{\circ}$ & \pm & $0,00055^{\prime \prime}$ \\
\hline Abril & 178.901 & 35,32 & $4,37^{\mathrm{s}}$ & \pm & $0,00056^{-}$ \\
\hline Maio & 170.074 & 44,04 & $4,36^{\circ}$ & \pm & $0,00057^{-}$ \\
\hline Junho & 153.014 & 51,89 & $4,41^{t}$ & \pm & $0,00060^{\prime \prime}$ \\
\hline Julho & 155.888 & 59,88 & $4,45^{\circ}$ & \pm & $0,00059^{\prime \prime}$ \\
\hline Agosto & 157.926 & 67,98 & $4,48^{n}$ & \pm & $0,00059^{\text {us }}$ \\
\hline Setembro & 150.967 & 75,72 & $4,48^{n}$ & \pm & $0,00059^{145}$ \\
\hline Outubro & 159.212 & 83,89 & $4,47^{i}$ & \pm & $0,00059^{-\prime}$ \\
\hline Novembro & 156159 & 91,90 & 4,471 & \pm & $0,00059^{-2}$ \\
\hline Dezembro & 158.038 & 100,00 & $4,45^{k}$ & \pm & $0,00059^{-\prime}$ \\
\hline TOTAL & 1.950 .034 & & & & \\
\hline
\end{tabular}

Alberton (2012), estudando a \% de lactose em diferentes estações do ano, observou maiores valores $(4,47 \%)$ no verão e menores $(4,40 \%)$ no outono. Bruhn e Franke (1976), trabalhando com rebanhos na Califórnia verificaram maiores concentrações de Lactose nos meses de primavera e menores nos meses de outono, sendo que Perez Júnior et al. (2002) obtiveram resultado semelhante em rebanhos no Paraná.
Gonzalez et.al. (2004) estudando a \% de lactose no Rio Grande do Sul, observou o menor valor no mês de Março $(4,30 \%)$ e maior em novembro $(4,54 \%)$. Segundo Rosa et.al. (2012), os meses de inverno apresentam teores maiores de lactose $(4,41 \%)$, o que se reflete em maior produção leite, e menores na primavera $(4,32 \%)$ nas amostras de tanque.

Também 0 ano de análise influenciou significativamente as \% de lactose $\quad(P<0,01)$, como podemos observar no resumo da análise de variância (tabela 3).

$\mathrm{Na}$ tabela 5, observamos menor estimativa de média ajustada para as \% de lactose no ano de 2005 (4,38\%), que aumentou linearmente até 0 ano de 2012, com a maior estimativa de média $(4,49 \%)$. O efeito de ano sobre características de qualidade reflete, de maneira geral um complexo de influências a que os animais estão sujeitos durante o ano. Essas podem ser justificadas por diferenças no clima, manejo, sanidade e alimentação. Bem como, poderão refletir mudanças genéticas no desempenho da população.

\begin{tabular}{|c|c|c|c|c|c|}
\hline \multirow{2}{*}{ ANO DE ANÁLISE } & \multirow{2}{*}{$\mathrm{N}$} & \multirow{2}{*}{$\%$} & \multicolumn{3}{|c|}{$\%$ LACTOSE } \\
\hline & & & Média $^{1}$ & \pm & EP \\
\hline 2005 & 125.257 & 6,42 & $4,38^{a}$ & \pm & $0,00065^{\prime \prime}$ \\
\hline 2006 & 186.438 & 15,98 & $4,41^{\mathrm{b}}$ & \pm & $0,00055^{*}$ \\
\hline 2007 & 262.332 & 29,44 & $4,4^{\mathrm{c}}$ & \pm & $0,00048^{-*}$ \\
\hline 2008 & 326.385 & 46,17 & $4,42^{\circ}$ & \pm & $0,00045^{-}$ \\
\hline 2009 & 337.243 & 63,47 & $4,41^{\mathrm{e}}$ & \pm & $0,00046^{-}$ \\
\hline 2010 & 276.463 & 77,65 & $4,47^{\circ}$ & \pm & $0,00048^{\prime \prime}$ \\
\hline 2011 & 287.339 & 92,38 & $4,48^{\circ}$ & \pm & $0,00047^{\prime \prime}$ \\
\hline $2012^{2}$ & 148.577 & 100,00 & $4,49^{\mathrm{h}}$ & \pm & $0,00064^{*}$ \\
\hline TOTAL & 1.950 .034 & & & & \\
\hline
\end{tabular}

O efeito de região influenciou significativamente as \% de lactose $(\mathrm{P}<0,01)$, como podemos observar no resumo da análise de variância (tabela $3)$. 
$\mathrm{Na}$ tabela 6, observamos menor estimativa de média ajustada para as \% de lactose na região Norte Pioneiro Cornélio Procópio $(4,40 \%)$, todavia a maior estimativa ocorreu na região Sudoeste - Francisco Beltrão (4,50\%). A variação observada no desempenho de diferentes regiões é geralmente esperada, podendo ser explicada pelas diferenças de ambiente geral, manejo sanitário, nutricional, constituição genética e intensidade de seleção.

Alberton (2012), estudando a \% de lactose em diferentes regiões no estado do Paraná, observou menor valor em Verê, Sudoeste $(4,36 \%)$ e maior em Tapejara, Noroeste $(4,46 \%)$.

\begin{tabular}{|c|c|c|c|c|c|}
\hline \multirow{2}{*}{$\begin{array}{l}\text { REGIÃO } \\
\text { MUNICIPIO SEDE }\end{array}$} & \multirow{2}{*}{ N } & \multirow{2}{*}{$\%$} & \multicolumn{3}{|c|}{$\%$ LACTOSE } \\
\hline & & & Média' ${ }^{1}$ & \pm & EP \\
\hline $\begin{array}{l}\text { 1. Noroeste } \\
\text { Umuarama } \mathrm{Cfa}\end{array}$ & 61.991 & 3,18 & $4,44^{\circ}$ & \pm & $0,00085^{\prime \prime}$ \\
\hline $\begin{array}{l}\text { 2. Centro Ocidental } \\
\text { Campo Mourão } \mathrm{Cfa}\end{array}$ & 414.991 & 24,46 & $4,45^{\mathrm{b}}$ & \pm & $0,00036^{\prime \prime}$ \\
\hline $\begin{array}{l}\text { 3. Norte Central } \\
\text { Londrina Cfa }\end{array}$ & 145.630 & 31,93 & $4,41^{\mathrm{C}}$ & \pm & $0,00059^{\prime \prime}$ \\
\hline $\begin{array}{l}\text { 4. Norte Pioneiro } \\
\text { Comélio Procópio } \mathrm{Cfa}\end{array}$ & 35.372 & 33,74 & $4,40^{d}$ & \pm & $0,00111^{\prime \prime}$ \\
\hline $\begin{array}{l}\text { 5. Centro Oriental } \\
\text { Ponta Grossa } \mathrm{Cfb}\end{array}$ & 138.721 & 40,86 & $4,46^{\circ}$ & \pm & $0,00061^{*}$ \\
\hline $\begin{array}{l}\text { 6. Oeste } \\
\text { Cascavel Cfa }\end{array}$ & 135.252 & 47,79 & $4,45^{f}$ & \pm & $0,00061^{\prime \prime}$ \\
\hline $\begin{array}{l}\text { 7. Sudoeste } \\
\text { Francisco Beltrăo Cfa }\end{array}$ & 73.903 & 51,58 & $4,50^{\circ}$ & \pm & $0,00079^{\prime \prime}$ \\
\hline $\begin{array}{l}\text { 8. Centro Sul } \\
\text { Guarapuava } \mathrm{Cfb}\end{array}$ & 502.468 & 77,35 & $4,42^{\mathrm{h}}$ & \pm & $0,00040^{\prime \prime}$ \\
\hline $\begin{array}{l}\text { 9. Sudeste } \\
\text { Irati Cfb }\end{array}$ & 51.142 & 79,97 & $4,40^{\prime}$ & \pm & $0,00094^{\prime \prime}$ \\
\hline $\begin{array}{l}\text { 10. Metropolitana de } \\
\text { Cunitiba } \mathrm{Cfb}\end{array}$ & 390.564 & 100,00 & 4,411 & \pm & $0,000422^{*}$ \\
\hline TOTAL & 1.950 .04 & & & & \\
\hline
\end{tabular}

Também a idade da amostra influenciou significativamente as \% de lactose $(\mathrm{P}<0,01)$, como podemos observar no resumo da análise de variância (tabela 3).

Na tabela 7, observamos maior estimativa de média ajustada para as \% de lactose em amostras com dois dias de idade $(4,44 \%)$, entretanto a menor estimativa de média foi observada em amostras com seis dias de idade $(4,42 \%)$. Bem como, observa-se que $68,07 \%$ das amostras de $\%$ de lactose foram analisadas até o terceiro dia, enquanto que $96,42 \%$ foram analisadas até o sexto dia. Monardes et al. (1996) relataram que no Canadá $93 \%$ das amostras foram analisadas até o terceiro dia.

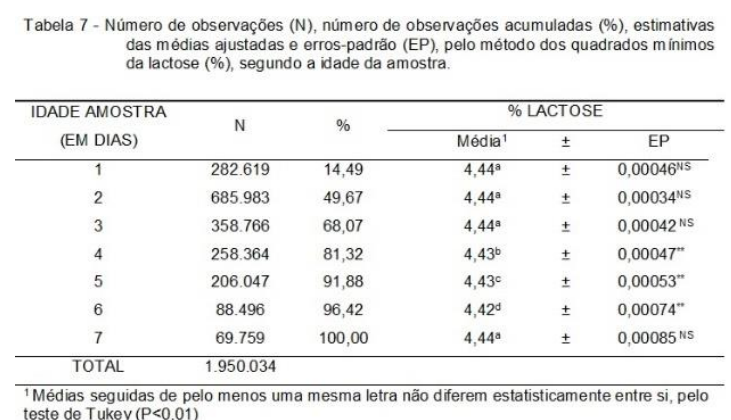

O efeito de escore da CCS (ECS) influenciou significativamente as \% de lactose $\quad(P<0,01)$, como podemos observar no resumo da análise de variância (tabela 3).

$\mathrm{Na}$ tabela 8, apresentamos as relações entre o ECS e a \% de lactose. Assim, quando a ECS variou de zero a oito (zero a 4.525 .000 células/ $\mathrm{mL}$ ) a \% de lactose diminuiu de 4,63 para $4,14 \%$, respectivamente.

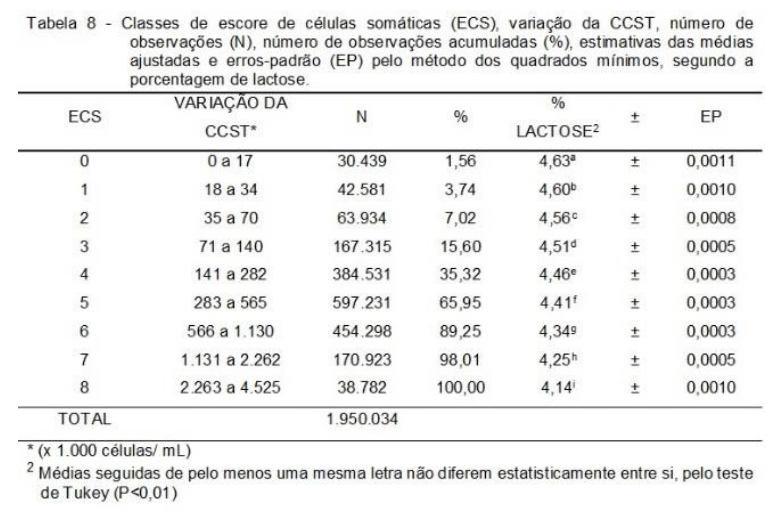

Segundo Rogers, Mitchell e Bartley (1989), Shuster, Harmon e Jackson (1991), Schukken et al. (1992a), Schaellibaum (2000) e Santos (2001), 
vacas com altas CCST e ECS apresentam diminuição na concentração de lactose no leite devido à passagem da mesma para o sangue, que pode ser comprovado pelas elevadas concentrações de lactose no sangue e na urina de vacas com mastite. Assim como a lesão tecidual ocasionada pela mastite provoca redução da capacidade de síntese de lactose pelo epitélio glandular, o que afeta significativamente a quantidade do leite produzido, devido ao papel central da lactose como regulador osmótico do volume do leite.

Outros pesquisadores, estudando as relações da \% de lactose com CCST e ECS, encontraram resultados semelhantes aos desta pesquisa, entre eles: Harmon (1994), Brito e Dias (1998), Silva et al. (2000), Schaellibaum (2000), Marques, Balbinotti e Fischer (2002), Machado, Pereira e Sarríes (2000) e Noro (2004).

A Correlação de Pearson obtida, foi alta e negativa entre a \% de lactose e - ECS $(-0,420)$, encontrando forte evidência estatística $(P<0,01)$ de que 0 valor esperado esteja relacionado com o ECS. Outros autores encontraram também correlações altas e negativas, entre eles, Bueno et al. (2005) e Pacheco (2011).

Rajcevic, Potocnik e Levstek, (2003) observaram correlação negativa entre CCS e \% de lactose $(r=-0,423)$, o que está próximo do valor encontrado nesta pesquisa.

A redução da \% de lactose seria resultado de menor síntese deste componente do leite em glândulas mamárias infectadas (Pereira, et al., 1997) e da utilização da lactose pelos patógenos intramamários (Auldist, et al., 1995).

Prada e Silva et al. (2000), analisando 1.361 amostras de leite, encontraram o aumento do escore de células somáticas com uma redução da concentração da lactose.

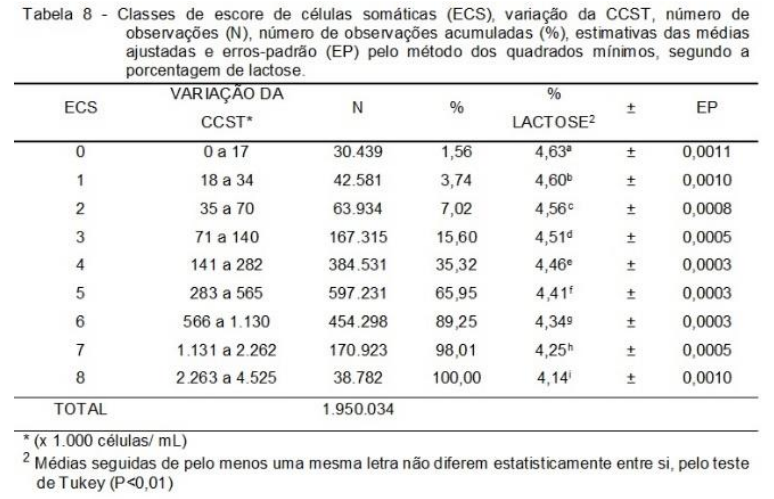

\section{CONCLUSÃO}

A grande frequência de amostras encontradas no ECS cinco ou menos $(65,95 \%)$, reflete um elevado nível de mastite nos rebanhos estudados, associado com significativa quantidade de quartos infectados, perdas na produção de leite e diminuição da \% de Lactose.

Frente aos resultados encontrados, fica evidente a necessidade por parte dos produtores e a das indústrias de reavaliarem seus programas que focam a saúde da glândula mamária correlacionando com o pagamento do leite por qualidade, incluindo a \% de Lactose e o escore da contagem de células somáticas, visando melhorar a qualidade da matéria-prima e 0 rendimento industrial.

\section{AGRADECIMENTOS}

Ao FUNDO PARANÁ da Secretaria da Ciência, Tecnologia e Ensino Superior pelo apoio financeiro, através da Fundação da Universidade Federal do Paraná para o Desenvolvimento da Ciência, da Tecnologia e da Cultura, que possibilitaram a realização deste projeto de pesquisa. 


\section{COMITÊ DE ÉTICA E BIOSSEGURANÇA \\ Esta pesquisa foi aprovada pelo Comitê de Etica no uso de animais da Universidade Federal do Paraná, protocolo n॰ 024/2011.}

\section{REFERÊNCIAS}

AKERS, R. M. 2002. Lactation and the Mammary Gland. 1st ed. lowa State Press, Ames.

ALBERTON, J. et al. Estudo da qualidade do leite de amostras obtidas de tanques de resfriamento em três regiões do estado do Paraná. Arquivos de Ciências Veterinárias e Zoologia da UNIPAR, Umuarama, v. 15, n. 1, p. 5-12, jan./jun. 2012.

ALI, A. K. A.; SHOOK, G. E. An optimum transformation for somatic cell concentration in milk. Journal of Dairy Science, Champaign, v. 63, p. 487-490, mar. $1980 . \quad$ Disponível em:<http://www.journalofdairyscience.or g/article/S0022-0302(80)82959-

6/abstract>. Acesso em: 14 nov. 2013. doi: 10.3168/jds.S0022-0302 (80) 829596.

AULDIST, M.J., COATS, S., ROGERS, G.L. et al. 1995. Changes in the composition of milk from healthy and mastitic dairy cows during the lactation cycle. Austr. J. Exp. Agric., 35(4):427436.

AULDIST, M.J.; WALSH, B.J. e THOMSON, N.A. Seasonal and lactational influences on bovine milk composition in New Zealand. J. Dairy Res., v.65, p.401-411, 1998.

BENTLEY INSTRUMENTS. 1995a. Bentley 2000 Operator's Manual. Chaska. p.77.
BENTLEY INSTRUMENTS. 1995b. Somacount 300 Operator's Manual. Chaska. p.12.

BRASIL. Ministério da Agricultura e do Abastecimento. Aprova os regulamentos técnicos de produção, identidade e quantidade do leite. Portaria n. 51, de 18 de setembro de 2002. Diário Oficial da República Federativa do Brasil, Brasília, DF, n. 321, 20 set. 2002.

BRASIL. Ministério da Agricultura e do Abastecimento. Altera a Instrução Normativa n. 51/2002. Portaria n. 62, de 30 de dezembro de 2011. Diário Oficial da República Federativa do Brasil, Brasília, DF, n. 251, 30 dez. 2011.

BRITO, J. R. F.; DIAS, J. C. A qualidade do leite. Juiz de Fora: Embrapa/Tortuga, 1998.

BRITO, J.R.; PORTUGAL, J.A (Eds.) Diagnóstico da qualidade do leite, impacto para a indústria e a questão dos resíduos de antibióticos. Juiz de Fora: Embrapa Gado de Leite, 2003. p.39-48.

BRUHN, J.C., FRANKE, A.A. (1976): Led and cadmium in California raw cow milk. J. Dairy Sci., 59, 1711-1717.

BUENO, V. F. F.; MESQUITA, A. J.; NICOLAU, E. S.; OLIVEIRA, A. N.; OLIVEIRA, J. P.; NEVES, R. B. S.; MANSUR, J. R. G.; THOMAZ, L. W. Contagem celular somática: relação com a composição centesimal do leite e período do ano no Estado de Goiás. Ciência Rural, Santa Maria, v. 35, n. 4, p. 848-854, jul./ago. 2005.

BUENO, V.F.F., MESQUITA, A.J., NICOLAU, E.S., OLIVEIRA, A.N., OLIVEIRA, J.P., NEVES, R.B.S., MANSUR, J.R.G., THOMAZ, L.W. Variações na composição centesimal do leite em função das contagens celular somática e bacteriana total no estado de Goiás. In: DURR, J.W., CARVALHO, 
M.P., SANTOS, M.V. O Compromisso com a Qualidade do Leite. Passo Fundo: Editora UPF, 2004, v.1, p. 301-306.

DURÃES, M.S.; FREITAS, A R.; COSTA, C.N. Influência da raça e do touro na qualidade do leite. Embrapa, Revista Balde Branco, São Paulo, p. 36-42, 2001.

DÜRR, J.V.Panorama da qualidade do leite na Região Sul: Rio Grande do Sul. In: BRITO, J.R.F.; PORTUGAL, J.A.B. Diagnóstico da qualidade do leite, impacto para a indústria e a questão dos resíduos de antibióticos. Juiz de Fora: Embrapa Gado de Leite, 2003. Cap.1, p.9-18.

DÜRR, J. W. et al. Milk recording as an indispensable procedure to assure Milk quality. Revista Brasileira de Zootecnia, Viçosa, v.40, p.76-81, 2011. Disponível em:

<http://www.revista.sbz.org.br/artigo/ind ex.php?artigo $=66262>$. Acesso em: 22 nov. 2013.

FONSECA, L.M., RODRIGUES, R., CERQUEIRA, M M.M.O.P., FONSECA, CS.P., LEITE, M.O., SOUZA, M.R.,PENNA, C. Situação da qualidade do leite cru em Minas Gerais. In: MESQUITA, A.J., DURR, J.W., COELHO, K.O. Perspectivas e avanços da qualidade do leite no Brasil. Goiânia: Talento, 2006, v.1, p.23-37.

GONZALEZ, H.L.; FISCHER, V.; RIBEIRO, M.E.R.; GOMES, J.F.; STUMPF JÚNIOR, W.; SILVA, M.A. da Avaliação da qualidade do leite na bacia leiteira de Pelotas, RS. Efeito dos meses do ano. Revista Brasileira de Zootecnia, v.33, n.6, p.1531-1543, 2004.

HARMON, R. J. Physiology of mastitis and factors affecting somatic cell counts. Journal of Dairy Science, Champaign, v. 77, n. 7, p. 2103-2112, 1994.
HARTMANN, W. Sólidos totais em amostras de leite de tanques. $56 \mathrm{f}$. Dissertação (Mestrado em Ciências Veterinárias) - Curso de Pós-Graduação em Ciências Veterinárias, Setor de Ciências Agrárias, Universidade Federal do Paraná, Curitiba, 1999.

HORST, J. A. Manual de Operações de Campo. Curitiba: Programa de Análise de Rebanhos Leiteiros do Paraná APCBRH, 2008.

HORST, J. A. Manual de Coleta de Amostras: Componentes e CCS. Curitiba: Programa de Análise de Rebanhos Leiteiros do Paraná APCBRH, 2010.

INSTITUTO AGRONÔMICO DO PARANÁ (IAPAR). Cartas climáticas do Paraná. Londrina: IAPAR, 1999.

INSTITUTO PARANAENSE DE DESENVOLVIMENTO ECONÔMICO E SOCIAL (IPARDES). Caracterização da indústria de processamento e transformação do leite no Paraná. Curitiba, 2010.

INSTITUTO PARANAENSE DE DESENVOLVIMENTO ECONÔMICO E SOCIAL (IPARDES). Caracterização socioeconômica da atividade leiteira no Paraná. Curitiba, Ipardes: 2009.

INSTITUTO PARANAENSE DE DESENVOLVIMENTO ECONÔMICO E SOCIAL (IPARDES). Leituras regionais: Regiões geográficas paranaenses: sumário. Curitiba, 2004.

KOEHLER, J. C. Caracterização da bovinocultura de leite no estado do Paraná. Curitiba:SEAB/DERAL, 2000.

MACHADO, P. F.; PEREIRA, A. R.; SARRÍES, G. A. Composição do leite de 
tanques de rebanhos brasileiros distribuídos segundo sua contagem de células somáticas. Revista Brasileira de Zootecnia, Viçosa, v. 29, n. 6, p. 18831886, 2000.

MACHADO, P.F.; CASSOLI, L.D.; COLDEBELLA, A. et al. Panorama da qualidade do leite na Região Sudeste: São Paulo. In: BRITO, J.R.; PORTUGAL, J.A (Eds.) Diagnóstico da qualidade do leite, impacto para a indústria e a questão dos resíduos de antibióticos. Juiz de Fora: Embrapa Gado de Leite, 2003. p.39-48.

MARQUES, L. T.; BALBINOTTI, M.; FISCHER, V. Variação da composição química do leite de acordo com a contagem de células somáticas. In: CONGRESSO PANAMERICANO DE QUALIDADE DO LEITE E CONTROLE DE MASTITE, 2., 2002, Ribeirão Preto. Anais... 1 CD ROM.

MEZZADRI, F. P., LEITE - A importância da Atividade Leiteira Familiar Paranaense,DERAL/SEAB,27ago.2012. Acesso em: 26 de maio, 2014. Online. Disponível em: http://www.agricultura.pr.gov.br/modules /qas/uploads/3186/leite_27agosto2012.p df.

MONARDES, H. G.; MOORE, R. K.; CORRIGAN, B.; RIOUX, Y. Milk preservatives under different systems of samples storage in Quebec, Canada. Journal of Food. Protection, Des Moines, v. 59, n. 2, p. 151-154, 1996.

MÜHLBACH, P.R.F.; OSPINA, H.; PRATES, E.R. et al. Aspectos nutricionais que interferem na qualidade do leite. In: ENCONTRO ANUAL DA UFRGS SOBRE NUTRIÇÃO DE RUMINANTES. Porto Alegre: UFRGS, 2000. p.73-102

NORO, G. Fatores ambientais que afetam a produção e a qualidade do leite em rebanhos ligados a cooperativas gaúchas. 92 p. Dissertação (Mestrado em Ciências Veterinárias) Universidade Federal do Rio Grande do Sul, Porto Alegre, 2004.

NZDG - New Zealand Dairy Group fo Companies - disponível em

http://www.nz.dairy.co. nz/public. Acesso em 25 de outubro de 2001.

OLIVEIRA, A.J, CARUSO, J.G.B. 1996. Leite - obtenção e qualidade do produto fluido e derivados. Piracicaba: FEALQ. 80p.

OSTRENSKY, A. Efeitos de ambientes sobre a contagem de células somáticas no leite de vacas da raça holandesa no Paraná. 114 f. Dissertação (Mestrado em Ciências Veterinárias) - Curso de PósGraduação em Ciências Veterinárias, Setor de Ciências Agrárias, Universidade Federal do Paraná, Curitiba, 1999.

PACHECO, M. S. Leite cru refrigerado do Agreste Pernambucano: caracterização da qualidade e do sistema de produção. 87 p. Dissertação (Mestrado em Ciências e Tecnologia de Alimentos) - Programa de Pós-Graduação em Ciência e Tecnologia de Alimentos, Universidade Federal Rural de Pernambuco, Recife: 2011.

PAULA, M. C.; RIBAS, N. P.; MONARDES, H. G.; ARCE, J. E.; ANDRADE, U. V. C. Contagem de Células Somáticas em Amostras de Leite. Revista Brasileira de Zootecnia, Viçosa, v. 33, n. 5, p. 1303-1308, 2004.

PEREIRA, A.R., MACHADO, P.F., BARANCELLI, G. et al. 1997. Contagem de células somáticas e qualidade do leite. Rev. dos Criadores, 67(807):19-21. 
PEREZ JUNIOR, F.; Porcentagem de gordura, proteína e lactose em amostras de leite de tanques. Dissertação (Mestrado em Ciências Veterinárias) Universidade Federal do Paraná, 2002.

PRADA-SILVA, L.F.; PEREIRA, A.R.; MACHADO, P.F.; SARRIÉS, G.A. 2000.

Efeito do nível de células somáticas sobre os constituintes do leite II. Lactose e

sólidos totais. Brazilian Journal of Veterinary Research and Animal Science

37:330-333.

RAJCEVIC, M.; POTOCNIK, K.; LEVSTEK, J. Correlations between somatic cells count and milk composition with regard to the season. Agric. Conspec. Sci., v.68, p.221-226, 2003.

ROGERS, S. A.; MITCHELL, G. E.; BARTLEY, J. P. The relationship between somatic cell count, composition and manufacturing properties of bulk milk 4. nonprotein constituents. Australian Journal of Dairy Technology, Highett, v. 44, n. 2, p.53-56, 1989.

ROSA, D. C.; TRENTIN, J. M.; PESSOA, G.A.; SILVA, C.A.M; RUBIN,M.I.B. Qualidade do leite em amostras individuais e de tanque de vacas leiteiras. Arquivos do Instituto Biológico, São Paulo, v. 79, n. 4, p. 485-493, 2012.

SANTOS, M. V. Contagem de células somáticas e qualidade do leite e derivados. In: SIMPÓSIO INTERNACIONAL SOBRE PRODUÇÃO INTENSIVA DE LEITE, 5., 2001, Belo Horizonte. Anais... Belo Horizonte, 2001. p. 115-127.

SANTOS, M. V.; FONSECA, L. F. L. Contagem de células somáticas e qualidade industrial do leite. In: CURSO ONLINE SOBRE A QUALIDADE DO
LEITE, 2., 2002. Disponível em: <http://www.milkpoint.com.br>. Acesso em: 20/04/2014.

SCHÄELLIBAUM, M. Efeitos de altas contagens de células somáticas sobre a produção e qualidade de queijos. In: SIMPÓSIO INTERNACIONAL SOBRE QUALIDADE DO LEITE, 2., 2000, Curitiba. Anais... Curitiba, 2000. p. 21-26.

SCHUKKEN, Y. H.; LESLIE, K. E.; WEERSINK, A. J.; MARTIN, S. W. Ontario bulk milk somatic cell reduction program. 1. Impact on somatic cell counts and milk quality. Journal of Dairy Science, Champaign, v. 75 , n. 12 , p. 3352-3358, 1992a.

SHOOK, G. E. Aproaches to summarizing somatic cell count which improve interpretability. In: NATIONAL MASTITIS COUNCIL ANNUAL MEETING, 21., 1982, Pennsylvanis. Procedings... Madison: National Mastitis Council, 1982. p. 150-166.

SHUSTER, D. E., HARMON, R. J., JACKSON, J. A. et al. Suppression of milk production during endotoxin-induced mastitis. Journal of Dairy Science, Champaign, v. 74 , n. 11 , p. 3763-3774, 1991.

SILVA, A. R. P.; OLIVEIRA, A. I. G.; GALVÃO, R. J. D.; MARTINEZ, M. L.; FREITAS, A. F.; NEIVA, R. S. Avaliação do desempenho produtivo de rebanhos da raça Pardo-Suiça no estado de São Paulo. Ciência e Agrotecnologia, Lavras, v. 24, n. 2, p. 458-467, 2000. 